\title{
BMJ Open Cervical cancer screening uptake and correlates among HIV-infected women: a cross-sectional survey in Côte d'Ivoire, West Africa
}

Boris Tchounga, ${ }^{\oplus 1,2}$ Simon Pierre Boni, ${ }^{1,3}$ Jean Jacques Koffi, ${ }^{1}$ Apollinaire G Horo, ${ }^{4}$ Aristophane Tanon, ${ }^{5}$ Eugène Messou, ${ }^{6}$ Serge-Olivier Koulé, ${ }^{7}$ Innocent Adoubi, ${ }^{3,8}$ Didier K Ekouevi, ${ }^{9,10}$ Antoine Jaquet ${ }^{10}$

To cite: Tchounga B, Boni SP, Koffi JJ, et al. Cervical cancer screening uptake and correlates among HIV-infected women: a cross-sectional survey in Côte d'Ivoire, West Africa. BMJ Open 2019;9:e029882. doi:10.1136/ bmjopen-2019-029882

- Prepublication history for this paper is available online To view these files, please visit the journal online (http://dx.doi. org/10.1136/bmjopen-2019029882).

Received 18 February 2019

Revised 02 July 2019 Accepted 04 July 2019
Check for updates

(C) Author(s) (or their employer(s)) 2019. Re-use permitted under CC BY-NC. No commercial re-use. See rights and permissions. Published by BMJ.

For numbered affiliations see end of article.

Correspondence to

Dr Boris Tchounga;

boris.tchounga@yahoo.fr

\section{ABSTRACT}

Objectives Despite the increasing number of interventions aiming to integrate cervical cancer screening into HIV clinics in sub-Saharan Africa, Women living with HIV (WLHIV) still have a high risk of developing cervical cancer. The aim of this study was to estimate the coverage of cervical cancer screening and associated factors among WLHIV in Abidjan, Côte d'Ivoire.

Design Cross-sectional survey conducted from May to August 2017.

Settings Outpatient setting in the four highest volume urban HIV clinics of government's or non-governmental organisation's sector in Côte d'Ivoire.

Participants All WLHIV, aged 25-55 years, followed since at least 1 year, selected through a systematic sampling procedure.

Intervention A standardised questionnaire administered to each participant by trained healthcare workers.

Outcome Cervical cancer screening uptake.

Results A total of 1991 WLHIV were included in the study, aged in median 42 years (IQR 37-47), and a median CD4 count (last known) of 563 (378-773) cells/mm $\mathrm{mm}^{3}$. Among the participants, $1913(96.1 \%)$ had ever heard about cervical cancer, 1444 (72.5\%) had been offered cervical cancer screening, mainly in the HIV clinic for 1284 (88.9\%), and 1188 reported a personal history of cervical cancer screening for an overall coverage of 59.7\% (95\% Cl 57.6 to 62.0). In multivariable analysis, university level (adjusted OR (aOR) 2.1; $95 \% \mathrm{Cl} 1.4$ to $3.1, \mathrm{p}<0.001$ ), being informed on cervical cancer at the HIV clinic (aOR 1.5; 95\% Cl 1.1 to $2.0, p=0.017$ ), receiving information self-perceived as 'clear and understood' on cervical cancer (aOR 1.7; 95\% Cl 1.4 to 2.2, $p<0.001$ ), identifying HIV as a risk factor for cervical cancer (aOR 1.4; 95\% Cl 1.1 to $1.8, p=0.002$ ) and being proposed cervical cancer screening in the HIV clinic (aOR 10.1; 95\% Cl 7.6 to 13.5, $\mathrm{p}<0.001$ ), were associated with cervical cancer screening uptake.

Conclusion Initiatives to support cervical cancer screening in HIV care programmes resulted in effective access to more than half of the WLHIV in Abidjan. Efforts are still needed to provide universal access to cervical cancer screening, especially among socioeconomically disadvantaged WLHIV.
Strengths and limitations of this study

- This study reports the cervical cancer screening coverage among women living with HIV in Côte d'Ivoire, a country with one of the highest HIV prevalence among women.

- The methodological approach used in this study allowed the enrolment of a quite representative sample of WLHIV visiting the participating HIV clinics.

- Reasons for not being screened and factors associated with cervical cancer screening uptake were explored through face-to-face interviews.

- The specificity of rural area was not directly explored with this population.

- The data collected are declarative information, collected through face-to-face interviews with possible memory and social desirability bias.

\section{INTRODUCTION}

Cervical cancer is the fourth most common cancer in women worldwide, with an estimated incidence of 570000 new cases and approximately $311 \quad 000$ new associated deaths in 2018. ${ }^{1}$ In sub-Saharan Africa (SSA), cervical cancer account for $20.8 \%$ of all cancers in women and $14.2 \%$ of all cancer-related deaths in women. ${ }^{2}$

Persistent infection with oncogenic human papilloma viruses (HPV) is a necessary cofactor for cervical cancer, responsible for the development of precancerous lesions that lead to invasive cervical cancer, if left untreated. ${ }^{3}$ Infection with HIV is known to accelerate the development of precancerous lesions leading to a higher risk of cervical cancer. ${ }^{45}$ Infection with HIV is also associated with more extensive lesions of the cervix, 3-5 times more common in women living with HIV/AIDS (WLHIV) than in those with no history of HIV. ${ }^{6-8}$ In addition, a twofold increase in the risk of death due to cervical 
cancer was reported in WLHIV compared with their HIV-negative counterparts. ${ }^{9}$

The long asymptomatic phase and slow disease progression from the persistent infection with oncogenic HPV to invasive carcinoma make cervical cancer a highly preventable cancer through screening and HPV immunisation. ${ }^{10}$ Since 2012, a cervical cancer prevention strategy based on integration of visual inspection of the cervix with acetic acid (VIA) in reproductive health and family planning services has been adopted in many African countries in order to increase access to cervical cancer screening services. ${ }^{11-13}$ Cervical cancer screening uptake among women in developed settings is relatively high, $79.4 \%$ in Brazil, ${ }^{14} 60 \%$ in $\mathrm{USA}^{15}$ and $89.1 \%$ in France, ${ }^{16}$ mainly with Pap smears. In low-income and middle-income countries, recent studies conducted in Ethiopia and Uganda revealed a low cervical cancer screening uptake of $23.5 \%$ and $30.3 \%$, respectively, ${ }^{17}{ }^{18}$ and emphasised the importance of sociodemographic factors and attitude of healthcare providers on the decision of beneficiaries to attend cervical cancer screening units. ${ }^{18} 19$

In West Africa, Cote d'Ivoire has the highest HIV prevalence among women $(4.1 \%) .{ }^{20}$ Cervical cancer is the second most common cancer among women accounting for $28.6 \%$ of all women's cancers and the leading cause of cancer deaths with $22.2 \%$ of all cancer-related deaths. ${ }^{2}$ The national guidelines for cervical cancer screening in the country are aligned with WHO guidelines for low -and-middle-income countries and recommend the screen-and-treat approach based preferentially on visual inspection with acetic acid or pap smear and cryotherapy or electrocoagulation, respectively. This recommendation targets women aged between 25 and 55 years in the general population, and those diagnosed with HIV who should be systematically offered a screening per year once linked to HIV care. ${ }^{21}$ These guidelines relied on the screening programme that was piloted in HIV clinics from 2008 to 2012 before being scaled up in all the government health facilities and at national level. However, data on the national coverage of cervical cancer screening among women in Côte d'Ivoire are currently not available. The only data available on the coverage of cervical cancer screening among WLHIV is the 10\% UNAIDS estimates based on the data from 2011 to 2012 Demographic and Health Survey. ${ }^{22}$ The aim of this study was to estimate the uptake of cervical cancer screening and its correlates among WLHIV in Abidjan, the economic capital of Côte d'Ivoire.

\section{METHOD}

\section{Study design and setting}

A cross-sectional survey was conducted from May to August 2017 among WLHIV followed in the four HIV clinics with the highest number of persons actively followed in Abidjan, Côte d'Ivoire. During the study period, all women aged 25-55 years, followed in these HIV clinics since at least 1 year, were eligible to participate.

\section{Sampling}

Participants were selected through a systematic sampling procedure. For every woman presenting at the HIV clinic for a routine follow-up visit, eligibility criteria were checked at the entrance desk and a sequential number was given to each eligible participant according to the arrival order. The first eligible participant of the day was selected and a sampling interval of three was applied to select subsequent participants. This procedure was repeated every day in each participating HIV clinics and a sticker was pasted on medical record of participants to avoid multiple enrolments of same participant.

\section{Data collection}

A standardised questionnaire was administered to each participant by trained nurses, midwives or social workers (psychosocial agents). The questionnaire was administered in French, the official language of the country, but each participant has the possibility to ask for a translator and a witness to assist in case she was not able to read or understand French. This questionnaire allowed the collection of data on demographics (age, education, marital status, monthly income), awareness of cervical cancer (existence of the disease, risk factors and prevention) and personal history of cervical cancer screening (date, place, provider, screening method, number of screening conducted). Additional HIV data (date of HIV infection diagnosis, history of CD4 count measures, clinical stage at enrolment into HIV care and antiretroviral therapy use) were extracted from the electronic records of the respective HIV clinics.

\section{Outcomes and variables}

To perform the logistic regression analysis, we defined the uptake of cervical cancer screening using the dichotomic variable 'at least one lifetime cervical cancer screening' (yes/no) as the dependent variable. Independent variables were demographic characteristics, HIV follow-up characteristics and variable related to awareness of cervical cancer (having heard about cervical cancer, being aware of the relationship with HIV, being aware of the cervical cancer prevention by screening, having been proposed the screening). The educational level was categorised into three modalities: 'no formal education or primary level' for women with no formal or primary education level, 'secondary level' for women who attend at least one class in secondary school and 'university level' for those with university education level. Age of participants was categorised into two modalities $(<45 / \geq 45)$ based on previous reports. The marital status was dichotomised as living alone (single, divorced, widowed) or living with a partner (married or engaged with a life partner). To characterise information of cervical cancer, we combine two variables (having heard about cervical cancer and source of information) to create a new variable indicating if the participants has been informed in the HIV clinic or elsewhere 'information on cervical cancer'. The time since first positive HIV serology was categorised into 
three modalities $(1-4 ; 5-9 ; \geq 10$ years). We also created a variable to assess the influence of the place and the category of person who proposed the screening, this variable 'proposition of screening' has two modalities for participants who had ever been proposed a screening (proposed elsewhere/proposed in the HIV clinic). The clinical stage was dichotomised into I-II/A-B for the participants with the corresponding WHO or CDC clinical stage in their medical records and III-IV/C for those with advanced stage disease.

\section{Statistical analysis}

Qualitative variables were described as frequencies with percentages and quantitative variables were described as medians with IQR. The $\chi^{2}$ test and Fisher's exact test were used for the comparison of qualitative variables. The $95 \%$ CI of the proportion of WLHIV covered by cervical cancer screening was estimated using the following formula: $\mathrm{p} \pm \mathrm{Z} * \sqrt{\mathrm{p}}(1 \mathrm{p}) / \mathrm{n}$ where $\mathrm{n}=$ sample size, $\mathrm{p}=$ ratio of the number of WLHIV covered by cervical cancer screening in the sample to the sample size and the $\mathrm{Z}$-value $=1.96$ for $95 \%$ CI. Logistic regression analysis using a stepwise backward procedure was performed to assess factors associated with uptake of cervical cancer screening among WLHIV. Multivariable analysis was performed including all available variables selected based on their potential association with uptake of cervical cancer screening from the existing literature. All analyses were performed using STATA V.12.0.

\section{Patient and public involvement}

Patients and public were not involved in the design of the study, but the questionnaire was submitted to a panel of WLHIV to identify unclear or confusing questions. Additional insights generated from this panel of women were taken into account in the final version of the questionnaire.

\section{Ethics statement}

Ethical approval was obtained from the 'Comité National d'Ethique des Sciences de la Vie et de la Santé (CNESVS)', that is, the National Ethic Committee for life Science and Health, the country's national IRB. The registry number of our study is 'IORG00075'. Each participant was given comprehensive information on the protocol of the study and had to provide a written consent before being enrolled.

\section{RESULTS}

\section{Sociodemographic and HIV follow-up characteristics}

During the study period, 1999 women attending their usual HIV clinic for routine follow-up visit were selected and proposed the study, among which eight $(0.04 \%)$ refused to participate because of lack of time. Overall, 1991 participants were interviewed with a median age of 42 years (IQR 37-47). Among them, 1736 (87.2\%) had no formal or primary level or secondary education, 1055
$(53.0 \%)$ were married or living with a partner, and 1052 $(52.8 \%)$ had no income or earned less than the national minimum wage (US\$109). For HIV-related characteristics, among the 1991 participants, 971 (48.8\%) were enrolled in the cohort with a WHO clinical stage I or II. The median CD4 count at enrolment in the cohorts was $287 \mathrm{cell} / \mathrm{mm}^{3}$ (IQR $140-459$ ), and the last known median CD4 count was 563 cell $/ \mathrm{mm}^{3}$ (IQR 378-773). The median follow-up duration was 8 years (IQR 4-11). Most participants $(94.9 \%)$ initiated antiretroviral treatment (ART) and the median duration on ART was 7 years (IQR 3-10).

\section{Knowledge on cervical cancer}

Off the 1991 participants, 1913 (96.1\%) had previously heard about cervical cancer, among which 1451 (75.8\%) heard about it in their follow-up HIV clinic. Among the 1913 participant who ever heard about cervical cancer, $1167(61.0 \%)$ stated that the information provided about cervical cancer was understandable and clear. Women with a university education level were more likely to receive a clear and understandable information about cervical cancer than those who were less educated $(78.4 \%$ vs $63.1 \%$ and $55.1 \% ; \mathrm{p}<0.001)$. Cervical cancer was recognised as a preventable disease by $1443(75.4 \%)$ participants, and screening and HPV vaccine were identified as preventive methods by $1299(90.0 \%)$ and 423 (29.3\%) participants, respectively. Women who reached university were more likely to identify screening as preventive method than the less educated ones $(94.8 \%$ vs $91.4 \%$ and $87.6 \%$, respectively, $\mathrm{p}=0.007$ ). Regarding risk factors for cervical cancer, multiple sexual partner and early sexual initiation were identified by $1238(64.7 \%)$ and $1113(58.2 \%)$ participants, respectively. Only 814 (42.5\%) participants identified HIV infection as a risk factor for cervical cancer, mainly women at university education level $(53.3 \%$ vs $41.5 \%$ and $40.5 \%$; $\mathrm{p}<0.001$ ) (table 1$)$.

\section{Cervical cancer screening uptake}

Among the 1991 participants, 1188 have ever been screened and the overall cervical cancer screening coverage among WLHIV was $59.7 \%$ (95\% CI (57.6 to $62.0)$ ). Overall, 1444 (72.5\%) participants had ever been offered cervical cancer screening, most of them in their follow-up HIV clinic $(88.9 \%)$. The main screening methods were VIA for 1050 (88.4\%) participants and Pap smear for $120(10.1 \%)$ participants. After cervical cancer screening, results were given to $1146(96.5 \%)$ women and only $778(65.5 \%)$ of them declared having received advise for repeated screening over time. Half of screened participants $(48.8 \%)$ declared having done the screening because it was advised by the healthcare workers, 328 $(27.6 \%)$ declared that it was their personal decision and $188(15.8 \%)$ declared having accept it because it was part of a research project in which they were involved. Among the $803(40.3 \%)$ women with no history of cervical cancer screening, the lack of information about cervical cancer $(54 \%)$, the fear of the result of cervical cancer screening 
Table 1 Knowledge on cervical cancer and prevention according to education level among women living with HIV in Côte d'Ivoire, West Africa

\begin{tabular}{|c|c|c|c|c|c|c|c|c|c|}
\hline \multirow[b]{2}{*}{ Characteristics } & \multicolumn{2}{|l|}{ Total } & \multicolumn{2}{|c|}{$\begin{array}{l}\text { No formal or } \\
\text { primary level }\end{array}$} & \multicolumn{2}{|c|}{ Secondary level } & \multicolumn{2}{|c|}{ University level } & \multirow[b]{2}{*}{$P$ value } \\
\hline & \multicolumn{2}{|c|}{$1991(100 \%)$} & \multicolumn{2}{|c|}{1057 (53.1\%) } & \multicolumn{2}{|c|}{$679(34.1 \%)$} & \multicolumn{2}{|c|}{$255(12.8 \%)$} & \\
\hline \multicolumn{10}{|l|}{ Ever heard about CC } \\
\hline Yes & 1913 & (96.1) & 991 & (93.8) & 667 & (98.2) & 255 & (100.0) & 0.000 \\
\hline \multicolumn{10}{|c|}{ Heard about CC in HIV clinic ( $N=1913)$} \\
\hline Yes & 1451 & (75.8) & 745 & $(75.2)$ & 512 & $(75.8)$ & 194 & $(76.1)$ & 0.758 \\
\hline \multicolumn{10}{|c|}{ Heard about CC in the media $(\mathrm{N}=1913)$} \\
\hline Yes & 1236 & $(64.6)$ & 570 & $(57.5)$ & 459 & $(68.2)$ & 207 & (81.2) & $<0.001$ \\
\hline \multicolumn{10}{|c|}{ Clarity of information received $(\mathrm{N}=1913)$} \\
\hline $\begin{array}{l}\text { Not clear / I did not } \\
\text { understand }\end{array}$ & 743 & $(39.0)$ & 445 & $(44.9)$ & 246 & $(36.9)$ & 55 & $(21.6)$ & $<0.001$ \\
\hline Very Clear / I understood it & 1167 & $(61.0)$ & 546 & $(55.1)$ & 421 & $(63.1)$ & 200 & $(78.4)$ & \\
\hline \multicolumn{10}{|l|}{$\begin{array}{l}\mathrm{CC} \text { is a preventable disease } \\
(\mathrm{N}=1913)\end{array}$} \\
\hline Yes & 1443 & $(75.4)$ & 707 & $(71.3)$ & 526 & (78.9) & 210 & $(82.4)$ & 0.001 \\
\hline \multicolumn{10}{|c|}{ Means of prevention for $\mathrm{CC}(\mathrm{N}=1443)$} \\
\hline Screening & 1299 & $(90.0)$ & 619 & $(87.6)$ & 481 & $(91.4)$ & 199 & $(94.8)$ & 0.007 \\
\hline Vaccine & 423 & (29.3) & 199 & $(28.1)$ & 131 & $(24.9)$ & 91 & $(43.3)$ & $<0.001$ \\
\hline \multicolumn{10}{|l|}{ Risk factors for CC $(\mathrm{N}=1913)$} \\
\hline HIV infection & 814 & (42.5) & 401 & $(40.5)$ & 277 & $(41.5)$ & 136 & (53.3) & $<0.001$ \\
\hline Multiple sexual partners & 1238 & $(64.7)$ & 612 & $(61.8)$ & 448 & $(67.2)$ & 178 & $(69.8)$ & 0.002 \\
\hline Early sexual initiation & 1113 & $(58.2)$ & 519 & $(52.4)$ & 424 & $(63.8)$ & 170 & $(66.7)$ & $<0.001$ \\
\hline
\end{tabular}

CC, cervical cancer.

(22\%), negligence (15\%) and fear of induced cost (10\%) were the main reasons (figure 1).

\section{Factors associated with cervical cancer screening uptake}

Being aged $\geq 45$ years (aOR $1.4 ; 95 \%$ CI 1.1 to $1.8, \mathrm{p}=0.012$ ), having a university education level (vs no or primary level education) (aOR 2.1; 95\% CI 1.4 to 3.1, $\mathrm{p}<0.001$ ), receiving information on cervical cancer through their HIV clinic (aOR 1.5; 95\% CI 1.1 to 2.0, $\mathrm{p}=0.017$ ), having

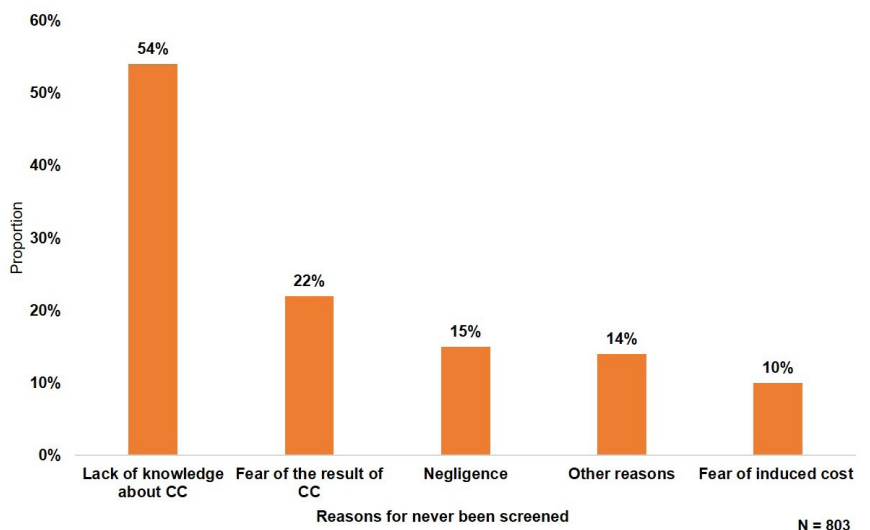

Figure 1 Reasons for not being screened for cervical cancer (CC) among women living with HIV in Côte d'Ivoire, West Africa. received information on cervical cancer self-perceived as 'clear' (aOR 1.7; 95\% CI 1.4 to 2.2, $\mathrm{p}<0.001$ ), attending their HIV clinic for at least 10 years (aOR 1.4; 95\% CI 1.0 to $1.8, \mathrm{p}=0.043$ ), identifying HIV as a risk factor of cervical cancer (aOR 1.4; 95\% CI 1.1 to $1.8, \mathrm{p}=0.002$ ) and being proposed cervical cancer screening in their HIV clinic (aOR 10.1; 95\% CI 7.6 to $13.5, \mathrm{p}<0.001$ ) were associated with cervical cancer screening uptake (table 2).

\section{DISCUSSION}

This study assesses the cervical cancer screening coverage among 1991 WLHIV in Abidjan, aged 42 years in median, with low education level and socioeconomic situation, and a clinically and immunologically stable HIV disease. The great majority of women were aware that cervical cancer was accessible to screening, but information received was clear and understood by less than two fifth of them. Uptake of cervical cancer screening was around $60 \%$ and was associated with higher education level, clarity of information, onsite cervical cancer screening and identifying HIV as a risk factor for cervical cancer. In addition, lack of information and fear of being diagnosed with cervical cancer were the main reasons reported by WLHIV for not accessing to cervical cancer screening. 
Table 2 Factors associated with uptake to cervical cancer screening among women living with HIV in Côte d'Ivoire, West Africa

\begin{tabular}{|c|c|c|c|c|c|}
\hline \multirow[b]{2}{*}{ Variables } & \multirow[b]{2}{*}{$n / N$} & \multicolumn{2}{|c|}{ Uni variable model } & \multicolumn{2}{|c|}{ Multivariable model (final) } \\
\hline & & $\begin{array}{l}\text { Adjusted OR (Cl } \\
95 \%)\end{array}$ & $P$ value & $\begin{array}{l}\text { Adjusted OR (CI } \\
95 \%)\end{array}$ & $P$ value \\
\hline \multicolumn{6}{|l|}{ Age (years) } \\
\hline$<45$ & $747 / 1293$ & 1 & - & 1 & - \\
\hline$\geq 45$ & $441 / 698$ & $1.3(1.0$ to 1.5$)$ & 0.019 & $1.4(1.1$ to 1.8$)$ & 0.012 \\
\hline \multicolumn{6}{|l|}{ Marital status } \\
\hline Living alone & $623 / 1083$ & 1 & - & - & - \\
\hline Living with a partner & $565 / 908$ & $1.2(1.0$ to 1.4$)$ & 0.033 & $1.3(1.0$ to 1.6$)$ & 0.046 \\
\hline \multicolumn{6}{|l|}{ Educational level } \\
\hline No formal / primary level & $568 / 1057$ & 1 & - & 1 & - \\
\hline Secondary level & $430 / 679$ & 1.5 (1.2 to 1.8$)$ & $<0.001$ & 1.2 (0.9 to 1.5$)$ & 0.211 \\
\hline University & $190 / 255$ & 2.5 (1.8 to 3.4$)$ & $<0.001$ & 2.1 (1.4 to 3.1$)$ & $<0.001$ \\
\hline \multicolumn{6}{|l|}{ Information on cervical cancer } \\
\hline Informed elsewhere & $135 / 535$ & 1 & & 1 & - \\
\hline Informed in usual HIV clinic & $1,053 / 1456$ & 7.7 (6.2 to 9.7$)$ & $<0.001$ & 1.5 (1.1 to 2.0$)$ & 0.017 \\
\hline \multicolumn{6}{|l|}{ Clarity of information } \\
\hline Not clear for me & $341 / 820$ & 1 & - & 1 & - \\
\hline Very clear for me & $847 / 1171$ & 4.0 (3.0 to 4.4$)$ & $<0.001$ & 1.7 (1.4 to 2.2$)$ & $<0.001$ \\
\hline \multicolumn{6}{|l|}{ Proposition of screening } \\
\hline Proposed elsewhere & $147 / 700$ & 1 & - & 1 & - \\
\hline Proposed in usual HIV clinic & $1041 / 1291$ & 15.7 (12.5 to 19.7$)$ & $<0.001$ & 10.1 (7.6 to 13.5$)$ & $<0.001$ \\
\hline \multicolumn{6}{|l|}{ Clinical stage } \\
\hline III-IV/C & $254 / 519$ & 1 & - & 1 & - \\
\hline I-II/A-B & $572 / 971$ & 1.5 (1.2 to 1.9$)$ & $<0.001$ & $1.6(1.2$ to 2.0$)$ & 0.001 \\
\hline Missing values & $362 / 501$ & 2.7 (2.1 to 3.5$)$ & $<0.001$ & 1.8 (1.3 to 2.5$)$ & $<0.001$ \\
\hline \multicolumn{6}{|l|}{ Follow-up duration } \\
\hline $1-4$ & $231 / 512$ & 1 & - & 1 & - \\
\hline $5-9$ & $431 / 720$ & 1.8 (1.4 to 2.3$)$ & $<0.001$ & $1.2(0.9$ to 1.7$)$ & 0.156 \\
\hline$\geq 10$ & $526 / 759$ & 2.7 (2.1 to 3.4$)$ & $<0.001$ & 1.4 (1.0 to 1.8$)$ & 0.043 \\
\hline \multicolumn{6}{|l|}{ Knowing HIV as a risk factor } \\
\hline No & $631 / 1172$ & 1 & - & 1 & - \\
\hline Yes & $557 / 819$ & 1.8 (1.5 to 2.2 ) & $<0.001$ & 1.4 (1.1 to 1.8$)$ & 0.002 \\
\hline
\end{tabular}

This study reports that three over five women living with HIV in our study population had been screened for cervical cancer at least once during the last 3 years. This result is higher than previous reports from Nigeria, Ethiopia and Uganda, where the cervical cancer screening uptake rates were $9.5 \%, 23.5 \%$ and $30.3 \%$, respectively. ${ }^{17} 1823$ This result support the successful integration of cervical cancer screening services in HIV clinics in Cote d'Ivoire. Indeed, since 2010, the national cancer control programme and the national aids control programme have been involved in the pilot phase of the cervical cancer prevention project (CECAP) supported by ministry of health and implementing partners. The aim was to integrate cervical cancer screening in HIV clinics and improve access to screening for women living with HIV, highly susceptible to cervical cancer. From 2010 to 2015, almost all HIV clinics in Abidjan and the outlying area were equipped for cervical cancer screening and their staff trained to provide cervical cancer screening and treatment of eligible precancerous lesions free of charge. ${ }^{21}$ The collaboration between AIDS and cancer control programmes led to this successful integration of services that has been described in other SSA countries as a game changer for the prevention of cervical cancer among HIV-infected women. ${ }^{24-26}$ The positive effect of this service integration is emphasised in our study by the 
association between screening uptake and the offer of cervical cancer screening 'onsite', in the HIV clinic were the participant is usually followed. This underlines the importance of scaling up the cervical cancer screening in all HIV clinics, as WLHIV will be more willing to accept the screening when proposed in the health facility they usually attend. Indeed, half of the screened women declared having accept the screening because it was advised by the healthcare worker at the HIV clinic. ${ }^{27}$

Despite the important coverage of cervical cancer screening reported in this study, around $40 \%$ of WLHIV have never been screened despite their high risk of developing an invasive cervical cancer, usually diagnosed at an advanced stage in SSA. ${ }^{28}{ }^{29}$ Lack of information was the main reason reported by WLHIV never screened for cervical cancer in Abidjan. This result suggests that despite efforts from the national cancer Control programme to increase awareness of cervical cancer among women (either in hospital-based strategy by training healthcare workers to offer cervical cancer screening or in community-based strategy through mass media (TV, radio, internet) and awareness campaign involving community mobilisers), messages to raise awareness on cervical cancer and its prevention remain poorly disseminated.

When analysing factors associated to cervical cancer screening uptake, it appears that highly educated women and those who identified HIV as a risk factor for cervical cancer were more likely to be screened. Thus, misunderstanding of information on cervical cancer remains an important barrier to screening among WLHIV as reported in other studies. ${ }^{30-33}$ In addition, the important gap $(36 \%)$ observed between the number of women who had been offered cervical cancer screening and those who have been effectively screened, reported in our population is consistent with previous study from Uganda. ${ }^{17}$ This result underlines the importance of a tailored communication strategy to take into account factors that influence the decision to undergo cervical cancer screening, such as low education level, the need for patient-centred communications and cultural beliefs reported in other SSA countries. ${ }^{30} 32$ In addition to participant-related barriers, providers-related barriers such as lack of knowledge and failure to inform or encourage women to be screened were reported as important factors influencing cervical cancer screening uptake in other SSA countries. ${ }^{33}$ In our study, the role of healthcare providers appeared to be central in the decision of WLHIV to get screened as highlighted by the strong association between screening uptake and proposition of screening in the usual HIV clinic of the participants. This idea is supported by the association reported between screening uptake and receiving clear and understood information on cervical cancer screening from healthcare providers. Thus, the high rate of cervical cancer screening uptake reported in this study compared with other SSA countries could be explained by the influence of healthcare providers, mostly psychosocial agent who are in charge of linkage and retention of WLHIV and who are trained to inform
WLHIV and refer them to screening unit. However, qualitative studies are needed to deeply explore the provider's related barriers for screening uptake among the $40 \%$ of WLHIV who have never been screened in the participating HIV clinics.

The WHO guideline for prevention and care of cervical cancer among women recommend for low-income and middle-income countries to perform VIA screening for all WLHIV aged between 30 and 49 years or older for those with visible transformation zone and to repeat the screening test within 3 years if no lesions. In case of precancerous lesions eligible for treatment, they will have to attend the screening unit 1 year after treatment for a follow-up visit with the aim of checking recurrence. ${ }^{34}$ To improve the uptake of cervical cancer screening, it is critical to improve health education and awareness among WLHIV, by reshaping the hospital-based communication approach for cervical cancer screening. A recent systematic review on strategies implemented in SSA to improve cervical cancer screening reported that about three quarter of these strategies include education and awareness activities, but most of them failed to demonstrate the effectiveness of the strategy. ${ }^{35}$ Most of these interventions had anticipated solution for financial barriers for clients, materials supply and capacity building of staff, while the main problem is to improve beneficiaries understanding of cervical cancer prevention messages. Usually, the level of communication on cervical cancer prevention services is standardised and not adapted to all the social categories. A specific educational programme, which uses culturally sensitive and linguistically appropriate strategies to deliver, tailored cervical cancer prevention messages could enhance awareness of WLHIV and increase access to cervical cancer screening. Furthermore, a collaboration between cervical cancer screening providers and community health educators is critical to improve the understanding of health education messages as already reported in SSA. ${ }^{36}$

This study was conducted among WLHIV followed in HIV clinics located in the urban area of Abidjan. These results may thus mostly reflect the feature in urban settings where people are more educated and more exposed to cervical cancer awareness activities than in rural settings. In addition, this study was conducted in the largest and oldest HIV clinics in Abidjan, where cervical cancer screening is provided free of charge since the initiation of CECAP in 2010 potentially overestimating the overall cervical cancer screening uptake in Abidjan. The cross-sectional design of the study did not allow us to draw any causal relationship between the uptake of cervical cancer screening and the reported associated factors. Given the relatively high prevalence of cervical cancer screening uptake, measures of association reported between this outcome and its correlates through OR have likely overestimated relative risks usually reported through prevalence ratio. While alternative modelling approaches such as a $\log$ binomial regression would have been more appropriate to provide risk estimates. However, as our main 
objective was to identify association between our covariates and the measure of cervical cancer screening uptake, a logistic regression model remains an adapted approach in this particular situation. ${ }^{37}$ Although the questionnaire was administered during face-to-face interviews by previously trained monitors, we cannot exclude bias related to the declarative nature of the collected information, such as memory bias or social desirability bias. However, the survey was conducted in the four largest HIV clinics in the country, using a daily-repeated systematic random selection procedure over a 4-month period. This enabled to take into account the heterogeneity of the population attending these HIV clinics and helped mitigate the risk of selection bias.

\section{CONCLUSION}

Initiatives to support cervical cancer screening in HIV care programmes have resulted in effective access to more than half of the WLHIV followed in the three major HIV clinics in Abidjan. Nevertheless, efforts are still needed to provide universal access to cervical cancer screening, which remains an AIDS-defining cancer poorly prevented by antiretroviral treatments compared with Kaposi Sarcoma or non-Hodgkin's lymphomas. Promoting cervical cancer screening among socioeconomically disadvantaged WLHIV by addressing client barriers still need to be prioritised.

\section{Author affiliations}

${ }^{1}$ Operations Research leDEA, Programme PACCI, Site ANRS, Abidjan, Lagune, Côte d'Ivoire

${ }^{2}$ Public Health Evaluation and Research, Elizabeth Glaser Pediatric AIDS Foundation, Yaounde, Center, Cameroon

${ }^{3}$ Research, Programme National de Lutte contre le Cancer, Abidjan, Lagune, Côte d'Ivoire

${ }^{4}$ Service de Gynécologie obstétrique, CHU de Yopougon, Abidjan, Lagune, Côte d'Ivoire

${ }^{5}$ Service des Maladies Infectieuses et Tropicales, $\mathrm{CHU}$ de Treichville, Abidjan, Côte d'Ivoire

${ }^{6}$ Centre de Prise en Charge de Recherche et de Formation CEPREF, Abidjan, Côte d'Ivoire

${ }^{7}$ Unité de soins ambulatoires et de conseils d'Abidjan, USAC, Abdjan, Côte d'Ivoire ${ }^{8}$ Service de cancérologie CHU de Treichville, Abidjan, Lagune, Côte d'Ivoire ${ }^{9}$ Département des Sciences Fondamentales et Santé Publique, Université de Lomé, Lome, Togo

${ }^{10}$ Centre Inserm 1219 and Institut de Santé Publique d'épidémiologie et de développement, Université de Bordeaux, Bordeaux, Girond, France

Acknowledgements We would like to warmly thank Pr François Dabis for his advises and orientation when designing and implementing the study, as well as Mr Azany Jean Claude for his strong support in data management and study monitoring.

Contributors BT and AJ designed the study. All authors supervised the study implementation and data collection. Statistical analysis was performed by BT, SB and AJ. Data interpretation and first draft of manuscript was done by BT, SB, JJK and AJ. Critical revision of the manuscript for important intellectual content was provided by all the coauthors who read and commented on the original manuscript and all agreed on the version finalised by BT, SB and AJ for submission.

Funding The study was conducted under the leDEA West Africa collaboration grants funded by the National Cancer Institute (NCl); Eunice Kennedy Shriver National Institute of Child Health \& Human Development (NICHD); National Institute of Allergy and Infectious Diseases (NIAID); Grant number: 5U01AI069919.
Competing interests None declared.

Patient consent for publication Not required.

Ethics approval Ethical approval was obtained from the 'Comité National d'Ethique des Sciences de la Vie et de la Santé (CNESVS)', that is, the National Ethic Committee for life Science and Health, the country's national IRB. The registry number of our study is 'IORG00075'.

Provenance and peer review Not commissioned; externally peer reviewed.

Data availability statement Data are available in a public, open access repository.

Open access This is an open access article distributed in accordance with the Creative Commons Attribution Non Commercial (CC BY-NC 4.0) license, which permits others to distribute, remix, adapt, build upon this work non-commercially, and license their derivative works on different terms, provided the original work is properly cited, appropriate credit is given, any changes made indicated, and the use is non-commercial. See: http://creativecommons.org/licenses/by-nc/4.0/.

\section{REFERENCES}

1. Bray F, Ferlay J, Soerjomataram I, et al. Global cancer statistics 2018: GLOBOCAN estimates of incidence and mortality worldwide for 36 cancers in 185 countries. CA Cancer J Clin 2018:68:394-424.

2. International Agency for Research on Cancer. Estimated number of incidence and deaths in 2018, WHO Africa region (AFRO), females, all ages [Internet]. IARC, WHO Cancer Today, 2018. Available: http:// gco.iarc.fr/today/home [Accessed 14 Jan 2019].

3. Xi LF, Demers GW, Koutsky LA, et al. Analysis of human papillomavirus type 16 variants indicates establishment of persistent infection. J Infect Dis 1995;172:747-55.

4. Clifford G, Franceschi S, Diaz M, et al. Chapter 3: HPV typedistribution in women with and without cervical neoplastic diseases. Vaccine 2006;24:S26-S34. 21 août.

5. Bonnet F, Lewden C, May T, et al. Malignancy-related causes of death in human immunodeficiency virus-infected patients in the era of highly active antiretroviral therapy. Cancer 2004;101:317-24.

6. Massad LS, Ahdieh L, Benning L, et al. Evolution of cervical abnormalities among women with HIV-1: evidence from surveillance cytology in the women's Interagency HIV study. J Acquir Immune Defic Syndr 2001;27:432-42.

7. Horo A, Jaquet A, Ekouevi DK, et al. Cervical cancer screening by visual inspection in Côte d'Ivoire, operational and clinical aspects according to HIV status. BMC Public Health 2012;12:237.

8. Cervical cancer and HIV-two diseases, one response. Available: https://www.unaids.org/en/resources/presscentre/featurestories/ 2018/october/cervical-cancer-and-hiv [Accessed 30 Mar 2019].

9. Dryden-Peterson S, Bvochora-Nsingo M, Suneja G, et al. Hiv infection and survival among women with cervical cancer. J Clin Oncol 2016;34:3749-57.

10. World Health Organization. WHO comprehensive cervical cancer control: a guide to essential practice. 2nd ed. Geneva, Switzerland: WHO, 2014.

11. Belhadj H, Rasanathan JJK, Denny L, et al. Sexual and reproductive health and HIV services: integrating HIV/AIDS and cervical cancer prevention and control. Int J Gynaecol Obstet 2013;121 Suppl 1:S29-S34.

12. Tchounga BK, Jaquet A, Coffie PA, et al. Cervical cancer prevention in reproductive health services: knowledge, attitudes and practices of midwives in Côte d'Ivoire, West Africa. BMC Health Serv Res 2014;14:165

13. White HL, Meglioli A, Chowdhury R, et al. Integrating cervical cancer screening and preventive treatment with family planning and HIVrelated services. Int J Gynecol Obstet 2017;138:41-6.

14. Barbosa IR. Regional and socioeconomic differences in the coverage of the Papanicolau test in Brazil: data from the Brazilian health survey 2013. Rev Bras Ginecol Obstet 2017;39:480-7.

15. Swan J, Breen N, Coates RJ, et al. Progress in cancer screening practices in the United States: results from the 2000 National health interview survey. Cancer 2003;97:1528-40.

16. Oussaid N, Lutringer-Magnin D, Barone G, et al. Factors associated with Pap smear screening among French women visiting a general practitioner in the Rhône-Alpes region. Revue d'Épidémiologie et de Santé Publique 2013;61:437-45.

17. Wanyenze RK, Bwanika JB, Beyeza-Kashesya J, et al. Uptake and correlates of cervical cancer screening among HIV-infected women attending HIV care in Uganda. Glob Health Action 2017;10:1380361.

18. Erku DA, Netere AK, Mersha AG, et al. Comprehensive knowledge and uptake of cervical cancer screening is low among women living 
with HIV/AIDS in Northwest Ethiopia. Gynecol Oncol Res Pract 2017;4.

19. Ebu NI. Sociodemographic characteristics influencing cervical cancer screening intention of HIV-positive women in the central region of Ghana. Gynecol Oncol Res Pract 2018;5.

20. Évaluation de l'impact du VIH dans la population générale en CÔTE D'IVOIRE, CIPHIA 2017-2018. Available: https://phia.icap.columbia. edu/wp-content/uploads/2018/09/3474CIPHIA_Cote-D27lvoire-SS_ FRENCH.v6.FINAL_.pdf [Accessed 4 Feb 2019].

21. National Cancer Control Program. National guidelines for the cervical cancer prevention. Cote d'Ivoire National Cancer Control Program (NCCP); 2013.

22. UNAIDS. Country factsheets Côte d'Ivoire 2017. Available: https:// www.unaids.org/en/regionscountries/countries/ctedivoire [Accessed 31 Mar 2019].

23. Ezechi OC, Gab-Okafor CV, Ostergren PO, et al. Willingness and acceptability of cervical cancer screening among HIV positive Nigerian women. BMC Public Health 2013;13:46.

24. Franceschi S, Jaffe H. Cervical cancer screening of women living with HIV infection: a must in the era of antiretroviral therapy. Clin Infect Dis 2007:45:510-3.

25. Odafe S, Torpey K, Khamofu H, et al. Integrating cervical cancer screening with HIV care in a district hospital in Abuja, Nigeria. Niger Med J 2013;54:176-84.

26. Renewed partnership to help end AIDS and cervical cancer in Africa. Available: https://www.pepfar.gov/press/releases/281984.htm [Accessed 31 Mar 2019].

27. Implementation science graphic brief in review: health benefits of linking women to cervical cancer screening in Zambia, 2016. Available: https://www.usaid.gov/what-we-do/global-health/hivand-aids/information-center/hiv-and-aids-research-corner/cervicalcancer-screening-zambia [Accessed 31 Mar 2019].
28. Dunyo P, Effah K, Udofia EA. Factors associated with late presentation of cervical cancer cases at a district Hospital: a retrospective study. BMC Public Health 2018;18.

29. Menon MP, Coghill A, Mutyaba IO, et al. Association between HIV infection and cancer stage at presentation at the Uganda cancer Institute. J Glob Oncol 2018;4:1-9.

30. Bukirwa A, Mutyoba JN, Mukasa BN, et al. Motivations and barriers to cervical cancer screening among HIV infected women in HIV care: a qualitative study. BMC Womens Health 2015;15:82.

31. Williams M, Kuffour G, Ekuadzi E, et al. Assessment of psychological barriers to cervical cancer screening among women in Kumasi, Ghana using a mixed methods approach. Afr Health Sci 2013;13:1054-61.

32. JNW L, Ojo AA. Barriers to utilisation of cervical cancer screening in sub Sahara Africa: a systematic review. Eur J Cancer Care 2017;26.

33. McFarland DM, Gueldner SM, Mogobe KD. Integrated review of barriers to cervical cancer screening in sub-Saharan Africa. J Nurs Scholarsh 2016;48:490-8.

34. World Health Organization, éditeur. WHO guidelines for screening and treatment of precancerous lesions for cervical cancer prevention. Geneva World Health Organization; 2013: 40.

35. Johnson LG, Armstrong A, Joyce CM, et al. Implementation strategies to improve cervical cancer prevention in sub-Saharan Africa: a systematic review. Implementation Sci 2018;13.

36. Uy C, Lopez J, Trinh-Shevrin C, et al. Text messaging interventions on cancer screening rates: a systematic review. J Med Internet Res 2017;19:e296.

37. Cook TD. Advanced statistics: up with odds ratios! a case for odds ratios when outcomes are common. Acad Emerg Med 2002;9:1430-4. 